\title{
SOLUBILITY ENHANCEMENT OF POORLY WATER SOLUBLE DRUGS BY VARIOUS TECHNIQUES
}

\author{
Sakshi Minocha ${ }^{1 *}$, Dr. Shilpa Pahwa ${ }^{1}$, Dr. Vandana Arora ${ }^{1}$ \\ ${ }^{1}$ LLOYD SCHOOL OF PHARMACY, LIMT, GREATER NOIDA, U.P
}

Article Info: Received 01 December 2018; Accepted 05 January. 2019

Cite this article as: Minocha, S., Pahwa, D. S., \& Arora, D. V. (2019). SOLUBILITY ENHANCEMENT OF POORLY WATER SOLUBLE DRUGS BY VARIOUS TECHNIQUES. Journal of Biomedical and Pharmaceutical Research, 8(1).

DOI: https://doi.org/10.32553/jbpr.v8i1.565

Address for Correspondence: Sakshi Minocha, LLOYD School of Pharmacy, LIMT, Greater Noida, U.P Conflict of interest statement: No conflict of interest

\section{ABSTRACT:}

Solubility is not the ability to dissolve or thaw a substance; it may happen not only due to dissolution but also because of a chemical reaction. Solubility is the phenomenon of dissolution of solid in liquid phase to provide a homogenous system. Solubility is one of the vital factors for accomplishing desired concentration of drug in systemic circulation for pharmacological response. Low aqueous solubility is the major problem seen with formulation development of new chemical entities as well as for the generic development. With all new discovered chemical entities about $40 \%$ drugs are lipophilic and doesn't shown therapeutic range due to their poor water solubility. Drug with poor water solubility shows slow dissolution rates, incomplete absorption and low bioavailability when taken orally. Drug solubility and bioavailability enhancement are the important in the formulation of pharmaceuticals. The Biopharmaceutics Classification System shows that Class II and IV drugs have low water solubility, poor dissolution, and low bioavailability. This review mentions different approaches used for the enhancement of the solubility of poorly water-soluble drugs that includes particle size reduction, $\mathrm{pH}$ adjustment, and solid dispersion. This describes the techniques of solubilizaton for the attainment of effective absorption and improved bioavailability. Keywords: Solubility, BCS classification, Bioavailability, Solid-dispersion.

\section{INTRODUCTION}

Although the oral route of drug administration is more preferable, but for many drugs it may be quite challenging and problematic. One of the most important factors is the solubility, mainly aqueous solubility of drug (Table I). A drug must have some aqueous solubility for achieving its therapeutic efficacy. It is seen that poor solubility is one of the most frequently encountered difficulties in the development of oral formulation ${ }^{1}$.
Table 1: Solubility of drug

\begin{tabular}{|l|l|}
\hline Evocative term & $\begin{array}{l}\text { Part of solvent required per } \\
\text { part of solute }\end{array}$ \\
\hline Very soluble & Less than 1 \\
\hline Freely soluble & From 1 to 10 \\
\hline Soluble & From 10 to 30 \\
\hline Sparingly soluble & From 30 to 100 \\
\hline Slightly soluble & From 100 to 1000 \\
\hline Very slightly soluble & From 1000 to 10,000 \\
\hline $\begin{array}{l}\text { Practically insoluble } \\
\text { or insoluble }\end{array}$ & 10,000 and more \\
\hline
\end{tabular}


Solubility enacts an active role in pharmaceutical dosage form. Solubility is welldefined as solute dissolve in specific solvent at exact temperature. In excess of $90 \%$ drug treated as orally. Drug absorption, bioavailability and pharmacokinetic profile are reliant on solubility parameter. Good solubility illustrates the upright dissolution and absorption ${ }^{2}$.

Extensive use of solubility from altered perception has led to solubility being stated in numerous ways. It is normally conveyed as a concentration, either by mass ( $g$ of solute per $\mathrm{kg}$ of solvent, g per $\mathrm{dL}(100 \mathrm{~mL})$ of solvent), molarity, molality, mole fraction, or other similar pictures of concentration. The benefit of stating solubility in this manner is its simplicity, although the disadvantage is it depends on the occurrence of other species in the solvent (e.g., the common ion effect) ${ }^{1(a)}$. Saturated solutions of ionic compounds of moderately low solubility are defined by solubility constants. It explains the balance among dissolved ions from the salt and undissolved salt. The value of this constant is independent of other species in the solvent.

\section{Need of Solubility:}

Drug absorption from the GI tract is restricted by diverse factors. The chief factor is the poor aqueous solubility and poor membrane penetrability of the drug molecule. When dispensed orally as an active vehicle it should first dissolve in gastric or intestinal fluids formerly it can pervade the membranes of the GIT to reach systemic circulation. Later, two areas of pharmaceutical research that emphasis to advance the oral bioavailability of active agents comprise; enriching of solubility and dissolution rate of poorly water soluble drugs $^{3}$. The BCS is a scientific agenda for organizing a drug substance built on its aqueous solubility and intestinal permeability. As per BCS class II \& IV drugs are rate limiting step in drug release from the dosage form and solubility in gastric fluid and not the absorption, so enhancing the solubility in succession increase the bioavailability for BCS class II \& IV drugs ${ }^{4}$.

\section{BCS CLASSIFICATION:}

Biopharmaceutical Classification System (BCS) is centered on solubility and permeability. Bioavailability of drug is influenced by three chief factors like solubility, permeability and dissolution (Fig 1). Bioavailability of drug is distinct as the rate and degree of drug which is present in systemic circulation at precise period of time.

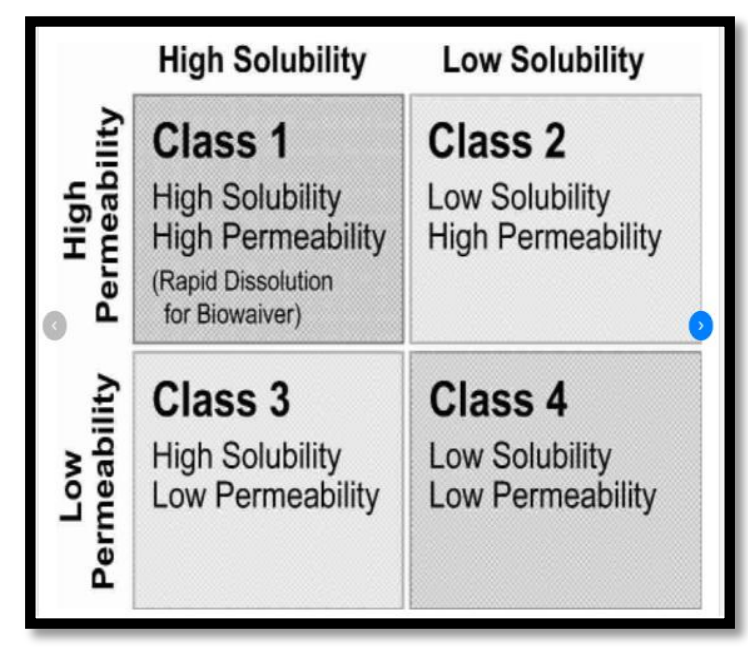

Fig. 1: BCS classification

The BCS is explained by four major classes and the drugs are classified according with three major factors governing bioavailability, namely, dissolution, solubility, and permeability.

Each class has its own characteristics and reflects suitability for a certain class of dosage forms and its relevance, or otherwise not, for controlled release.

- The development of drug delivery systems for a class I drug is most challengeable for achieving a targeted release profile. Formulations in this include both the control of release rate and physiochemical properties of drugs like the $\mathrm{pH}$-solubility profile of the drug.

- The drug development for class II drugs are based on the micronization, lyophilization, 
addition of surfactants, and use of complexing agents.

- The class IV drugs present a major challenge for the development of drug delivery systems and for their route of choice, due to their poor solubility and permeability characteristics. These are mainly administered by parenteral route with the formulation containing solubility enhancers.

\section{Importance of solubility enhancement}

1. Solubility is one of the important parameters for achieving desired concentration of drug in systemic circulation for required pharmacological response

2. Hydrophobic drugs require high doses and high dosage regimens to impact therapeutic plasma concentrations after administration

3. Low aqueous solubility is the main problem encountered with preparation and development of NCEs as well as for generic drugs

4. For orally administered drugs solubility is the one of the important rate limiting parameters to reach their desired concentration in complete circulation for pharmacological response.

5. Water is the solvent of excellent for liquid pharmaceutical formulations

6. Most of the drugs like weakly acidic or weakly basic having poor aqueous solubility

7. Poorly water-soluble drugs having slow drug absorption leads to insufficient and gastrointestinal mucosal toxicity and variable bioavailability ${ }^{5}$.

\section{Techniques for Solubility Enhancement:}

When the solubility of substances in aqueous media is limited, formulation techniques are required in the drug discovery and they are of critical importance for lead substance selection and commercial drug product development ${ }^{6}$

- Physical Modification : Particle size reduction corresponding micronization and nano-suspension, alteration of the crystal pattern like polymorphs, amorphous form and co-crystallization, drug diffusion in carriers like eutectic combinations, solid dispersions, solid solutions and cryogenic procedures.

- Chemical Modifications: Variation of ph, usage of buffer, derivatization, complexation, and salt formation.

- Miscellaneous Methods: Supercritical fluid process, application of adjuvant identical surfactant, solubilizers, co-solvency, hydrotrophy, and new excipients.

\section{Particle Size Reduction:}

The solubility of drug is associated to drug particle size; as particle befits smaller, the surface area to volume ratio surges. The greater surface area permits greater interaction with the solvent that produces an expansion in solubility.

Usual methods of particle size reduction, comprises comminution and spray drying, depend on upon mechanical stress to disaggregate the active compound. Particle size reduction is a competent, reproducible, and profitable method of solubility improvement. The mechanical force are intrinsic for milling and grinding, frequently symbols important amounts of physical stress upon the drug product and affects its degradation. Micronization is alternative usual technique for the particle size reduction. Micronization surges the dissolution rate of drugs over increased surface area; it does not increase equilibrium solubility. Reducing the particle size of drugs, cause increase in surface area, advance their rate of dissolution. Micronization of drugs is ended by milling techniques using jet mill, rotor stator colloid mills ${ }^{7}$.

These procedures are utilized on griseofulvin, progesterone, spironolactone diosmin, and fenofibrate. For each drug, micronization enhances their digestive absorption, and consequently their bioavailability and clinical efficacy. Micronized fenofibrate show more than 10 -fold $(1.3 \%$ to $20 \%)$ growth in 
dissolution in at 30 minutes bio-relevant media $^{8,9}$.

\section{pH ADJUSTMENT:}

Poorly water soluble drugs through portions of the molecule which can be protonated (base) or deprotonated (acid) might be dissolved in water by pertaining a $\mathrm{pH}$ alteration. $\mathrm{PH}$ modification can be used for both oral and parenteral administration. By intravenous administration the poorly soluble drug may precipitate as blood is a strong buffer with $\mathrm{pH}$ between $7.2-7.4$. For this method, the buffer capacity and acceptability of the particular $\mathrm{pH}$ are significant to consider. In the stomach the $\mathrm{pH}$ is around 1 to 2 and in the duodenum the $\mathrm{pH}$ is between 5-7.5, so for oral administration the solubility is also likely be influenced as the drug passes through the intestines. Ionizable compounds that are stable and soluble after $\mathrm{pH}$ adjustment are best used. It can also be applied to crystalline as well as lipophilic poorly soluble compounds ${ }^{10-13}$. Solubilized excipients that increase environmental $\mathrm{pH}$ within a dosage form, such as a tablet or capsule, higher than pKa of weakly-acidic drugs increases the solubility of that drug, excipients which act as alkalizing agents may increase the solubility of weakly basic drugs ${ }^{14,15}$.

The solubility of the poorly soluble drug can be enhanced as associated to water alone. $\mathrm{pH}$ alteration is merged with co-solvents to surge the solubility of the poorly soluble drug. If the precipitation upon dilution is acceptable or amorphous, bioavailability can be improved due to an increased concentration rise and enhanced surface area for dissolution. If precipitation of the poorly soluble drug happens irrepressibly after contact with a $\mathrm{pH}$ at which the drug is much less soluble (oral as well as parenteral), the interpretation of the results may be misleading.

Advantages:

- $\quad$ Easy to express and analyse.

- $\quad$ Simple to manufacture and fast track.
- Usages of small amounts of compound, amenable to high throughput evaluations.

Disadvantages:

- Possibility for precipitation by dilution with aqueous media obligating a $\mathrm{pH}$ at which the compound is less soluble. This leads to emboli, orally it can cause variability.

- Acceptability and toxicity (local and systemic) linked with the usage of a nonphysiological $\mathrm{pH}$ and severe $\mathrm{pHs}$.

- As through all solubilized and dissolved procedures, a dissolved drug in an aqueous atmosphere is commonly less stable chemically associated to formulations crystalline solid. The certain $\mathrm{pH}$ may quicken hydrolysis or catalyze further degradation mechanisms.

\section{Use of Surfactant:}

Permeability and dissolution rate could be improved with surfactant. Absorption rate likewise be boost due to enhancing of particle size. Mechanism includes initially wettability and then permeation of solvent in the particles of drug. Solubility of ample poorly water soluble anti-microbial drugs can be improved by use of surfactant. Surfactant are of three types; anionic, cationic and non-ionic. Anionic and cationic are choice over the non-ionic surfactant. It deeds as good solubilizing agent $^{16}$.

\section{Solid dispersion:}

Solid dispersion is the utmost imperative method for improving of solubility of poorly water soluble drugs. It also surges the bioavailability by physical variation. Solid dispersion is categorized into six categories; solid solution, eutectic mixtures, glass suspensions, amorphous precipitates, complex and above combinations. Solid dispersion mends the solubility and dissolution rate by decreasing the wettability and porosity. Solid dispersion can be formulated by solvent evaporation, hot melt extrusion, co-grinding \& supercritical method, etc ${ }^{17}$. 
Advantage of Solid Dispersion:

1. Identical delivery of drug molecules into carriers is attained.

2. It raises the wettability of drug molecules and therefore improves the solubility of drugs.

3. Various carriers are used in solid dispersion technique includes urea, colic acid, cellulose and bile salt aimed at surface activity.

4. Carriers of solid dispersion have elevated porosity which progresses the solubility by faster release of drug $^{18}$.

\section{Carriers used in Solid Dispersion:}

1. Polyethylene glycol (PEG): PEG is consumed as carrier for formulation of solid dispersion of numerous drugs. PEG with molecular weight, 1500-20000 is generally used. When molecular weight of PEG is raised then viscosity also increases that maintains the steadiness of solid dispersion. PEG is water as well as various organic solvent soluble that are used in solvent evaporation method. PEG has low melting point below at $65{ }^{\circ} \mathrm{C}$ that can be used for fusion method. It has suitable solubility property which expands the wettability. Polyethylene glycol developed by interface of ethylene oxide with water ${ }^{19}$.

2. Hydroxypropyl methylcellulose (HPMC): It is cellular derived, hydrophilic media which are utilized as carrier for controlled drug release and solid dispersion formulation. It is nontoxic, inexpensive and simply well-suited with other drug. It is available in various viscosity grades $^{20}$.

3. Polyvinylpyrrolidone (PVP): PVP is used for formulation of solid dispersions by solvent evaporation method. It has effective solubility and miscibility with organic solvent. It is nonionic polymer attain by polymerization. It is obtainable in various grades like PVP $\mathrm{K} 3 \mathrm{O}^{21}$.

\section{(A) Melting method:}

Drug and carrier are blended by means of mortar \& pestle. For attaining a regular dispersion, its combination is heated at or beyond the melting point of all the constituents. It is cool down to obtain a firm mass. It is then crushed and sieved.

\section{(B) Solvent Evaporation Method:}

Tachibana and Nakamura ${ }^{22}$ stood the first to dissolve drug and carrier in a common solvent and then vaporize the solvent beneath vacuum to create a solid solution. This made a solid solution of the extremely lipophilic $\beta$-carotene in the very water soluble carrier povidone. This method can be employed efficaciously for enhancement and constancy of solid dispersions of poorly water soluble drugs ${ }^{23,24}$. The foremost benefit of this technique is that thermal decay of drugs or carriers can be prohibited due to low temperature essential for the evaporation of organic solvents. The drawbacks with this method are the greater cost of formulation, trouble in completely eliminating the organic solvent, the probable adverse result of the insignificant amount of the solvent on the chemical stability of the drug, the choice of a common volatile solvent, and the inconvenience in producing crystal forms ${ }^{25}$.

\section{Conclusion:}

Solubility is the most important physical characteristic of a drug for its oral bioavailability, formulation, development of different dosage form of different drugs, therapeutic efficacy of the drug and for quantitative analysis. Proper selection of solubility enhancement method is important for a good formulation like good oral bioavailability, reduces frequency of dosing and better patient compliance with a low cost of production. The different techniques described above can be used alone or in combination to enhance the solubility of the drug. Because of solubility problem the bioavailability of many drugs gets affected and hence solubility enhancement becomes necessary. 


\section{References:}

1. Limbachiya MI. Solubility enhancement techniques for poorly soluble drugs: A review. IJPRD, 2011; 4(4):71-86

2. Reddy AT, Srinivasan $S$, Kavitha $K$ and Kumar Rupesh: Better solubility enhancement of poorly water soluble drugs. Int.J.Inv.Pharm.Sci. 2013; 1(4): 267273)

3. Patil MS, Godse SG, Saudagar RB. Solubility Enhancement by Various Techniques: An Overview. World Journal of Pharmacy and Pharmaceutical Sciences. 2013; 2(6):4558-4572.

4. Pawar AR, Choudhari PD. Novel Techniques for Solubility, Dissolution Rate and Bioavailability.Enhancement of Class II \& IV drugs. Asian Journal of Biomedical \& Pharmaceutical Science. 2012; 13:9-14.

5. Dhillon B, Goyal NK, Malviya R, Sharma PK. Poorly water soluble drugs: Change in solubility for improved dissolution characteristics a review. Glob J Pharmacol 2014;8:26-35.

6. Vemula VR, Lagishetty $V$, Lingala $S$. Solubility enhancement techniques, International Journal of Pharmaceutical Sciences Review and Research. 2010; 5(1):41-51.

7. N. Blagden, M. de Matas, P. T. Gavan, and P. York, "Crystal engineering of active pharmaceutical ingredients to improve solubility and dissolution rates," Advanced Drug Delivery Reviews, vol. 59, no. 7, pp. 617-630, 2007.

8. M. Vogt, K. Kunath, and J. B. Dressman, "Dissolution enhancement of fenofibrate by micronization, cogrinding and spraydrying: comparison with commercial preparations," European Journal of Pharmaceutics and Biopharmaceutics, vol. 68, no. 2, pp. 283-288, 2008.

9. J. C. Chaumeil, "Micronization: a method of improving the bioavailability of poorly soluble drugs," Methods and Findings in
Experimental and Clinical Pharmacology, vol. 20, no. 3, pp. 211-215, 1998.

10. Gennaro A.R. editors. Remington, the science and practice of pharmacy, 21st ed. Lippincott, Williams \& Wilkins, 2005; 867868.

11. Fiese E.F, Hagen T.A. Preformulation. In: Lachman L, Liberman H.A, Kanig J.L, editors. The theory and practice of industrial pharmacy. 3rd ed. Bombay: Varghees Publication House, 1990; 171196.

12. Allen L.V, Popovich, N.G, Ansel H.C., Ansel's Pharmaceutical Dosage Forms and Drug Delivery Systems, Lippincott, Williams \& Wilkins 2005; 100-101.

13. Venkatesh S, Y, Rao V, Anderson B. D, Intrinsic solubility estimation and $\mathrm{pH}$ solubility behavior of cosalane (NSC 658586), an extremely hydrophobic diproticacid, Pharmaceutical Research, 1996;13(10), 1453-1459.

14. Graham $H$, McMorland $M$, Joanne $D$, Wayne K, Peggy L.E, James E.A, James H.K.K, David R.G, Kerri R. Effect of $\mathrm{pH}$ adjustment of bupivacaine on onset and duration of epidural analgesia in parturients, 1986; 33(5), 537-541.

15. Jain A, Ran Y, Yalkowsky S.H, Effect of $\mathrm{pH}$ Sodium Lauryl Sulfate combination on solubilization of PG- 300995 (an Anti-HIV Agent), AAPS PharmSciTech.2004; 5(3), 4548.

16. Jason MV, Williams RO, Johnston KP: Formulation of danazol micronized by evaporative precipitation into aqueous solution, Bio aqueous solubilization service, Dowpharma, www.dowpharma.com.

17. Ahire B. R, Rane B. R, Bakliwal S. R, Pawar S. P: Solubility Enhancement of Poorly Water Soluble Drug by Solid Dispersion Techniques. International Journal of PharmTech Research, Vol.2, No.3, pp 2007

18. Wairkar SM and Gaud RS: Solid Dispersions: Solubility Enhancement 
Technique for Poorly Soluble Drug. International Journal of Research in Pharmaceutical and Biomedical Sciences, Jul-Sep 2013; Vol. 4(3): 848

19. Wairkar SM and Gaud RS: Solid Dispersions: Solubility Enhancement Technique for Poorly Soluble Drug, International Journal of Research in Pharmaceutical and Biomedical Sciences Jul- Sep 2013; Vol. 4(3): 849.

20. D.A. Alderman: A review of cellulose ethers in hydrophilic matrices for oral controlled-release dosage forms. Int. J. Pharm. Technol. Prod. Manuf.5 (1984) 1-9.

21. B.V. Robinson, F.M. Sullivan, J.F. Borcelleca, S.L. Schwartz, PVP. Acritical review of the kinetics and toxicology of Polyvinylpyrrolidone. (Povidone). 1990; Chelsea, Lewis Publishers.

22. T. Tachibana and A. Nakamura, "A methode for preparing an aqueous colloidal dispersion of organic materials by using water-soluble polymers: dispersion of $\beta$-carotene by polyvinylpyrrolidone," Colloid and Polymer Science, vol. 203,no. 2, pp. 130-133, 1965.

23. N. Blagden, M. de Matas, P. T. Gavan, and P. York, "Crystal engineering of active pharmaceutical ingredients to improve solubility and dissolution rates," Advanced Drug Delivery Reviews, vol. 59, no. 7, pp. 617-630, 2007.

24. J. C. Chaumeil, "Micronization: a method of improving the bioavailability of poorly soluble drugs," Methods and Findings in Experimental and Clinical Pharmacology, vol. 20, no. 3, pp. 211-215, 1998.

25. "Nanosuspension drug delivery technology and application nanotechexpress pharma pulse.htm,www.expresspharmapulse.com 